\title{
INSIGHTS COMPORTAMENTAIS SOBRE A DOAÇÃO DE ÓRGÃOS: COMO A ECONOMIA COMPORTAMENTAL PODE CONTRIBUIR PARA O DÉFICIT DE ÓRGÃOS PARA TRANSPLANTE
}

\author{
Behavioral insights on organ donation: How can behavioral economics contribute \\ to the deficit of organs for transplantation
}

Patricia Fonseca

\begin{abstract}
RESUMO
De acordo com dados recentes, no Brasil $43 \%$ das famílias entrevistadas não autorizam a doação dos órgãos de seus familiares. Compreender, portanto, as variáveis atuantes e o complexo processo de tomada de decisão na doação de órgãos torna-se fundamental para que novos esforços, visando elevar as taxas de consentimento no país sejam implementados. O presente trabalho visa apresentar características comportamentais com potencial de enriquecer a compreensão sobre o processo de tomada de decisão na doação de órgãos como framing, status quo, normas sociais, inércia e procrastinação, além de revelar experimentos e aplicações em políticas públicas inspiradas em tais insights já realizados ao redor do mundo e seus respectivos resultados. Trata-se de estudo reflexivo, baseado no referencial teórico da Economia Comportamental (behavioral economics). Conclui-se, a partir da presente reflexão, que as características comportamentais relatadas apresentam potencial explanatório relevante. Incorporá-las ao modelo atual de tomada de decisão na doação de órgãos não só indica possível contribuição para o esforço da abordagem familiar, mas também o direcionamento de campanhas sobre o tema e, futuramente, melhor desenho do ambiente de escolhas (nudge).
\end{abstract}

Descritores:Doação de Órgãos; Economia Comportamental; Tomada de Decisão.

Instituição:

Pesquisadora independente. Soudoador.org - São Paulo/SP

\section{INTRODUÇÃO}

Correspondência:

Patricia Fonseca

Rua Cipriano Barata, 1749 - Apto. 61 - CEP 04205-001 - São Paulo/SP,

Tel.: 11-992030301

E-mail: patricia@soudoador.org
Aceito em: 02/05/2017
Mundo afora, é possível coletarmos diversos exemplos tanto a nível experimental quanto de políticas aplicadas que demonstram como os insights das ciências comportamentais e a maior compreensão do papel de vieses, limitações cognitivas e motivações sociais no comportamento humano podem contribuir para desenhar políticas públicas mais eficientes na área da Saúde. ${ }^{1}$ 
Em outras palavras, isso significa ser possível contribuir para a saúde das pessoas e salvar vidas com menos investimento financeiro e maior criatividade e embasamento comportamental na hora de desenhar uma ação pública. A Saúde Comportamental nada mais é do que a aplicação da Economia Comportamental na área da Saúde, e traz consigo imenso potencial a ser explorado.

O processo de tomada de decisão individual passa por várias etapas, como coleta de informações, avaliação, julgamento e decisão. Em cada um desses momentos, uma série de vieses comportamentais influenciam de forma sistemática e previsível a tomada de decisão. ${ }^{2,3}$

\section{OBJETIVO}

Apresentar conceitos comportamentais que podem iluminar aspectos da tomada de decisão na doação de órgãos. Atualmente no Brasil, $43 \%$ das famílias ainda negam a doação dos órgãos de seus familiares. ${ }^{4}$ Compreender, portanto, quais fatores influenciam e impactam o processo decisório de ser um doador de órgãos ou de autorizar a doação dos órgãos de familiares pode contribuir para que sejam desenhadas novas estratégias visando elevar as taxas de consentimento no país.

Inspirado pelo referencial teórico da Economia Comportamental (behavioral economics), a análise aqui conduzida visa investigar características comportamentais com potencial de enriquecer a compreensão sobre o processo de tomada de decisão de doação de órgãos, além de revelar experimentos e aplicações em políticas públicas inspiradas em tais insights já realizadas ao redor do mundo e seus respectivos resultados.

\section{MÉTODO}

Trata-se de estudo reflexivo, construído com base no referencial teórico da Economia Comportamental e na literatura nacional e internacional. Para tanto, realizouse revisão da literatura, com a sistematização de informações pertinentes ao objetivo proposto, incluindo a análise de artigos científicos, livros e relatórios internacionais.

\section{RESULTADOS E DISCUSSÃO}

O presente trabalho apresenta cinco conceitos comportamentais com potencial explanatório relevante sobre a tomada de decisão de doação de órgãos: framing, status quo, normas sociais, inércia e procrastinação. Adicionalmente, destacam-se dois estudos aplicados que concluíram ser possível elevar o número de doadores registrados em cadastros nacionais através de framing ${ }^{5}$ e elevar as taxas de consentimento através do uso de regras pré-definidas. ${ }^{6}$

\section{O papel do "Enquadramento": O modo como falamos importa tanto quanto o que falamos}

Uma série de estudos vem sendo conduzida ao longo das últimas décadas e revelam a existência do que chamamos de "efeito enquadramento" (framing effect). ${ }^{7-9}$ A forma como a informação é apresentada pode não só impactar no processo decisório, mas em alguns casos, promover até a reversão de preferências das escolhas.

Esse efeito pode ser observado no clássico experimento da "doença asiática" conduzido pelos pesquisadores Amos Tversky e Daniel Kahneman. ${ }^{7}$ Nesse estudo, era informado que os Estados Unidos deveriam optar entre dois tipos de tratamento (A ou B) para uma doença asiática incomum, cuja expectativa era matar 600 pessoas. No enquadramento positivo (Quadro 1), as pessoas eram informadas que:

Quadro 1 - Experimento da Doença Asiática (Enquadramento Positivo)

\begin{tabular}{|l|c|}
\hline \multicolumn{1}{|c|}{ Opção } & Resultado \\
\hline $\begin{array}{l}\text { Se o Governo adotar } \\
\text { o Programa A }\end{array}$ & 200 pessoas serão salvas \\
\hline $\begin{array}{l}\text { Se o Governo adotar } \\
\text { o Programa B }\end{array}$ & $\begin{array}{c}1 / 3 \text { de probabilidade que 600 pessoas seriam } \\
\text { salvas e } 2 / 3 \text { de probabilidade que ninguém } \\
\text { seria salvo. }\end{array}$ \\
\hline
\end{tabular}

Fonte: Adaptado pelos autores de Tversky e Kahneman $(1981)^{7}$

Já no enquadramento negativo, as pessoas recebiam a mesma informação, mas enquadrada de forma diferente, conforme o Quadro 2 abaixo:

Quadro 2: Experimento da Doença Asiática (Enquadramento Negativo)

\begin{tabular}{|c|c|}
\hline Opção & Resultado \\
\hline $\begin{array}{c}\text { Se o Governo adotar o } \\
\text { Programa A }\end{array}$ & 400 pessoas irão morrer \\
\hline $\begin{array}{c}\text { Se o Governo adotar o } \\
\text { Programa B }\end{array}$ & $\begin{array}{c}1 / 3 \text { de probabilidade que ninguém morreria e } 2 / 3 \\
\text { de probabilidade de que todos morreriam. }\end{array}$ \\
\hline
\end{tabular}

Fonte: Adaptado pelos autores de Tversky e Kahneman (1981) ${ }^{7}$

Observou-se que, quando confrontadas com 0 enquadramento positivo, $71 \%$ das pessoas escolheram a opção A, de menor risco (salvar 200 pessoas 
com certeza). Quando a mesma questão e mesmas probabilidades eram apresentadas de forma negativa, $72 \%$ das pessoas escolheram a opção oposta e mais arriscada, ou seja, a opção B (preferiam o risco de que todos morressem do que a certeza de que alguém morreria), revelando uma reversão das preferências sobre risco e da escolha em si. ${ }^{7}$

Esse tipo específico de enquadramento é conhecido como "enquadramento da escolha sob risco" e ocorre quando duas opções com diferentes níveis de risco são apresentadas, tanto de forma positiva quanto negativa (alteração de valência), podendo impactar e até reverter a preferência de risco de um indivíduo. Em geral, as pessoas tendem a aceitar mais risco quando confrontadas com um enquadramento negativo..$^{10}$

Um exemplo interessante de como o conceito de enquadramento pode contribuir para o tema da doação de órgãos é a aplicação feita pelo Behavioral Insights Team (time de especialistas em Economia Comportamental da Inglaterra) em conjunto com o governo britânico (DH - Department for Health, NHSBT - National Health Blood and Transfusion Service e GDS - Government Digital Service). O estudo contou com a participação de 1.035 .000 indivíduos. ${ }^{5}$

Neste experimento testou-se diferentes frases inspiradas em diferentes características comportamentais como aversão às perdas, reciprocidade, normas sociais entre outras, buscando encontrar um melhor enquadramento que promovesse a ação de se registrar como doador de órgãos logo após o término do processo online de renovação da carteira de motorista. A ideia era também tentar superar a inércia e deixar a escolha de ser doador mais saliente. Ao todo, foram testadas sete frases, conforme demonstrado no Quadro 3.

Quadro 3: Experimento sobre o papel do enquadramento na taxa de registro como doador de órgãos.

\begin{tabular}{|l|l|}
\hline \multicolumn{1}{|c|}{ Conceito comportamental } & \multicolumn{1}{c|}{ Frase testada } \\
\hline Grupo Controle & $\begin{array}{l}\text { Grupo de indivíduos que ao final da renovação da carteira apenas visualizou: “Por favor cadastre- } \\
\text { se no Registro de Doadores de Órgãos”. Os demais visualizam uma frase antes desse convite }\end{array}$ \\
\hline Enquadramento positivo & Você pode salvar ou transformar a vida de até nove pessoas como doador de órgãos \\
\hline Enquadramento negativo & Três pessoas morrem todos os dias porque não há doadores suficientes. \\
\hline Reciprocidade & Se você precisasse de um transplante de órgãos, você faria? Se sim, por favor, ajude os outros. \\
\hline Chamada para a ação & Se você apoia a doação de órgãos, por favor, transforme seu apoio em ação. \\
\hline Normal social & Todos os dias, milhares de pessoas que veem essas páginas decidem se registrar. \\
\hline Normal social e foto de multidão & Todos os dias milhares de pessoas que veem essa página decidem se registrar + foto \\
\hline $\begin{array}{l}\text { Normal social e logo do NHBTS (essa versão serviu } \\
\text { como controle para a foto da opção norma e foto) }\end{array}$ & Todos os dias milhares de pessoas que veem essa página decidem se registrar + logo \\
\hline
\end{tabular}

Fonte: Adaptado de Sanders e Hallworth, $2015^{5}$

Os pesquisadores identificaram que mesmo uma frase curta pode ser suficiente para engajar indivíduos a se registrarem como doadores. Uma frase apresentou impacto $39 \%$ melhor que o grupo controle (reciprocidade), enquanto outra frase teve impacto $5 \%$ pior que o controle (norma e foto). A ideia por trás da versão "normal social e foto" era ativar a saliência, mas parece ter impactado as pessoas negativamente quando aliada à imagem de multidão. O controle feito no experimento com a versão "norma e logo" permitiu mostrar que não foi a existência da foto, mas daquela foto específica, já que a versão "norma e logo" não teve performance pior que o controle. ${ }^{5}$

Segundo os autores Michael Sandes e Michael Hallworth (2015), um desenho com a inspiração comportamental adequada poderia trazer pelo menos 95.000 potenciais doadores adicionais para o sistema inglês por ano.
Adicionalmente, o fato de uma frase ter obtido resultados inferiores ao controle ressalta a importância das políticas serem devidamente testadas e avaliadas do ponto de vista comportamental antes de serem aplicadas em larga escala. Como os próprios autores ressaltam, caso aquela frase específica fosse arbitrariamente escolhida, pessoas poderiam morrer em função da escassez de órgãos. ${ }^{5}$

A literatura sobre o efeito enquadramento aponta para a existência de um fenômeno consistente e recorrente. A forma como a informação é enquadrada importa e pode impactar nas preferências e ocasionar até reversão da escolha. Dito isto, vale ressaltar que muitas vezes, não há espaço para comunicação neutra, ou seja, uma valência tem que ser aplicada, e essa última desempenhará papel sobre o processamento da informação. ${ }^{11-13}$ No caso da doação de órgãos, a eficiente abordagem comportamental do tema e o adequado enquadramento 
podem significar aumento das taxas de consentimento no país. Ressalta-se que o desenvolvimento de experimentos voltados para o sistema brasileiro de doação e transplantes é necessário.

Por fim, vale pontuar que a existência do efeito enquadramento está associada ao fato de que a tomada de decisão individual acontece muitas vezes de forma automática e intuitiva, baseada em heurísticas mentais e regras de bolso. Alguns estudos anularam ou mitigaram o efeito enquadramento estudado ao pedir para que as pessoas justificassem suas escolhas, pensassem em voz alta ou ponderassem por mais três minutos. Já outros trabalhos apontaram que o efeito enquadramento pode ser exacerbado e reforçado quando as decisões eram tomadas em grupo..$^{13}$ Outro ponto a ser levantado é que descrições positivas ou negativas podem invocar associações positivas ou negativas na memória, impactando a análise individual. Emoções também parecem ser uma variável explicativa desse fenômeno; estudo com autistas, por exemplo, não observou o efeito enquadramento entre eles. ${ }^{14}$

\section{Norma social e status quo: é mais fácil seguir o grupo}

De modo geral, as pessoas têm a tendência de seguir ou optar pela norma social, ou seja, o comportamento que é socialmente desejado ou esperado. Isso porque decidir é custoso e cansativo, e seguir o que a maioria opta pode ser um facilitador. O desvio da norma pode ser percebido como um risco e indivíduos em geral sofrem de aversão ao risco (é melhor perder com a maioria do que ganhar sozinho). ${ }^{7}$

Nesse sentido, promover feedback do comportamento social atual pode funcionar como sinalizador do caminho a seguir. Num experimento clássico em economia de energia, as pessoas recebiam junto com suas contas de luz a informação da média do consumo no bairro. Os resultados foram bastante promissores e a maioria das pessoas que estava acima da média reduziu seu consumo pessoal no mês subsequente. $O$ julgamento individual funciona com bases relativas e não absolutas, por isso prover uma referência serve como parâmetro para ajustes do comportamento individual.

Tal experimento sofreu um efeito boomerang indesejado no primeiro momento, pois indivíduos que estavam abaixo da média de consumo no bairro elevaram seu consumo na sequência. Isso foi resolvido com um reforço social, que se deu ao adicionar um "smile sorrindo" na conta de luz para aqueles que estavam abaixo da média. Com isso, anulou-se tal efeito e quem estava abaixo da média manteve seu consumo reduzido. ${ }^{15}$

Do mesmo modo, sinalizar as taxas de aprovação para doação de órgãos ou taxas de registro de doadores pode influenciar a tomada de decisão para doação de órgãos. Uma sugestão interessante foi observada no local de registro para doadores do estado americano de Illinois (Donate Life Illinois) que informava, antes de convidar o indivíduo a ser doador, que " $87 \%$ dos adultos de Illinois acreditavam que se registrar como doador era a coisa certa a se fazer" e, na sequência, informava que " $60 \%$ dos adultos em Illinois estão registrados como doadores". Prover informação que dê referência social do comportamento desejado ou esperado pode facilitar a tomada de decisão de ser doador de órgãos para brasileiros.

\section{Inércia e procrastinação: é mais fácil deixar como está}

O comportamento humano é fortemente influenciado por características comportamentais conhecidas como inércia e procrastinação. Trata-se da tendência a deixar as coisas como estão ou deixá-las para depois. E o impacto disso é que tendemos a ficar com a opção inicial ou pré-definida de um dado cenário por pura inércia. ${ }^{2,16}$

No caso da doação de órgãos, um exemplo interessante desse fenômeno pode ser observado nos dados a seguir: nos Estados Unidos, $85 \%$ da população aprova a doação de órgãos e, no entanto, apenas $28 \%$ registraramse como doadores. Apesar de parte significativa da população apoiar a doação de órgãos, boa parte falha em se registrar como doador e efetivar a ação. Nos Estados Unidos, a opção inicial é não ser doador (consentimento explícito), de modo que deixar as coisas como estão (inércia) é permanecer como não doador. ${ }^{17}$

Para estudar o papel da opção pré-definida na doação de órgão, os pesquisadores Eric Johnson e Daniel Goldstein conduziram uma série de experimentos. ${ }^{6}$ O primeiro experimento foi online e contou com 161 participantes. Três cenários foram testados conforme - Quadro 4 a seguir. Participantes foram designados aleatoriamente para um dos três casos e recebiam apenas uma pergunta. A mudança de status poderia ser feita com apenas um click.

Quadro 4: Experimento online sobre o papel da regra pré-definida na doação de órgãos

\begin{tabular}{|l|l|}
\hline $\begin{array}{l}\text { Opção inicial era não ser doador } \\
\text { (Consentimento explícito) }\end{array}$ & $\begin{array}{l}\text { "Você acabou de se mudar para } \\
\text { um estado onde a opção pré- } \\
\text { definida sobre doação de órgãos } \\
\text { é não ser um doador, você deseja } \\
\text { confirmar ou mudar esse status?" }\end{array}$ \\
\hline $\begin{array}{l}\text { Opção inicial era ser doador - } \\
\text { (Consentimento presumido) }\end{array}$ & $\begin{array}{l}\text { "Você acabou de se mudar para } \\
\text { um estado onde a opção pré- } \\
\text { definida sobre doação de órgãos } \\
\text { é ser um doador, você deseja } \\
\text { confirmar ou mudar esse status?" }\end{array}$ \\
\hline $\begin{array}{l}\text { Opção inicial neutra - } \\
\text { (Escolha mandatória) }\end{array}$ & $\begin{array}{l}\text { "Você deseja ser um doador de } \\
\text { órgãos?" }\end{array}$ \\
\hline
\end{tabular}

Fonte: Adaptado de Johnson e Goldstein (2003) 6 
Mesmo em um ambiente tão simplificado, o estudo observou o seguinte resultado: simplesmente mudando a opção inicial de "não doador" para "doador", a taxa de disposição a doar passou de $42 \%$ para $82 \%$, conforme a Figura 1 abaixo, explicitando o poder da inércia no comportamento humano. Estudos apontam que a necessidade de preencher formulários, enviar e-mails ou fazer ligações já aumentava a probabilidade de o indivíduo ficar com a opção inicial. ${ }^{6}$

Figura 1: Taxas de consentimento do experimento online em função da regra pré-definida

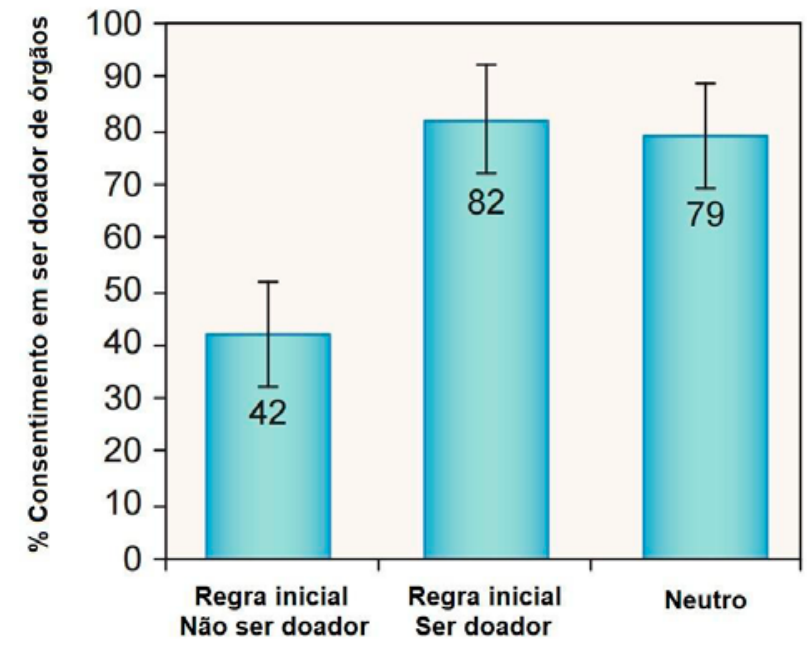

Fonte: Extraído de Johnson e Goldstein (2003) ${ }^{6}$

Interessante observar que $79 \%$ dos que foram designados para a opção inicial neutra (escolha mandatória) optaram por ser doadores, um número muito mais próximo do observado com a regra inicial de ser doador. ${ }^{6}$ Tal fato chama a atenção e levanta o questionamento se o fator inércia poderia ser capaz de se sobrepor às preferências individuais no comportamento sobre doação de órgãos.

Num segundo momento de seu experimento, Johnson e Goldstein (2003) compararam as taxas de consentimento de países com diferentes regras iniciais para doação (consentimento explícito versus consentimento presumido). ${ }^{6}$ Segundo os autores, foi possível observar que a regra pré-definida tem efeito forte sobre o comportamento na doação, conforme mostra a Figura 2,

Para Richard Thaler e Cass Sunstein, ${ }^{16}$ dois importantes economistas comportamentais, o poder da inércia e da opção pré-definida ficam claros no comparativo entre a Áustria e a Alemanha. Apesar de serem países com culturas semelhantes, na Alemanha, onde a regra inicial era não ser doador, as taxas de consentimento foram de $12 \%$, enquanto na Áustria, onde a opção inicial era ser doador, as taxas bateram os $99 \%$. Tais diferenças mantiveram-se mesmo controlando variáveis como religião, condição econômica e educacional dos agentes, o que vem reforçar a tese de que a regra prédefinida tem desempenhado papel importante nessa decisão. ${ }^{6}$

Figura 2: Taxas de consentimento para doação de órgãos, por país.

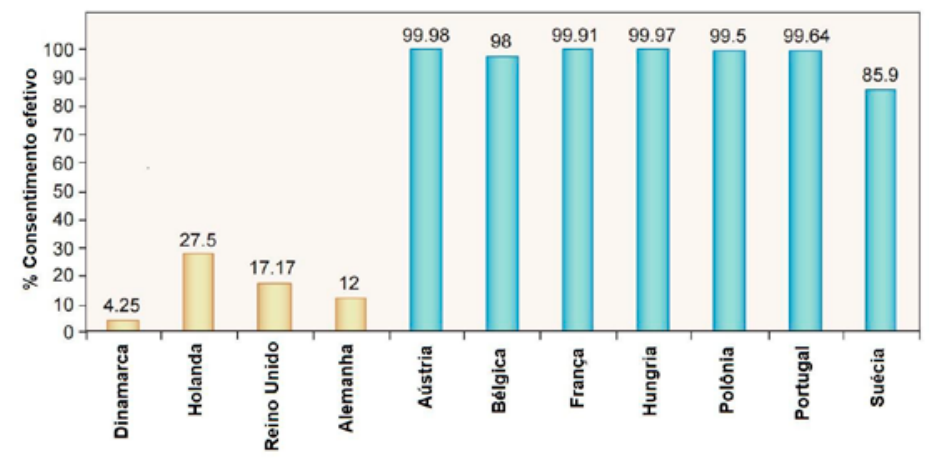

Fonte: Extraído de Johnson e Goldstein (2003) - Em dourado, países com opção inicial de não ser doador (consentimento explícito) e, em azul, países com opção inicial de ser doador (consentimento presumido). ${ }^{6}$

Pesquisadores pontuaram também que muitas pessoas podem enxergar a regra pré-definida como sugestão implícita, um curso de ação a ser tomado. Existe certo status quo por trás de uma regra pré-definida. É como se ao invés de ouvir a pergunta: "você deseja doar?", você ouvisse: "você não deseja doar?". É sutil, mas pode fazer toda a diferença.

Considerando o cenário brasileiro, onde muitas famílias deixam para decidir sobre suas preferências acerca da doação de órgãos no momento da perda do familiar, a questão pode ficar ainda mais delicada. A maioria delas no fundo, prefere não encarar a decisão num momento estressante emocionalmente, como o da perda de um ente querido (e talvez nem tenha recursos emocionais e cognitivos para tal). Nesse momento, manter-se com a decisão pré-definida é a opção menos custosa e de menor risco.

Desse modo, muitas famílias podem acabar não doando, não como exercício de suas preferências, fruto da decisão ponderada, mas muito mais como uma fuga de qualquer esforço decisório. Nessa linha, o relatório americano "Organ Donation: Opportunities for Action" citou que as organizações de fornecimento de órgãos e equipes de hospitais poderiam abordar as famílias de forma bastante distinta, como os familiares de um "doador" e não como os familiares de um "não doador". 
Essas simples mudanças poderiam facilitar a aceitação da doação de órgãos por parte dos familiares e, assim, elevar as taxas de doação. ${ }^{17}$

Forçoso lembrar, no entanto, que apenas alterar a regra inicial e facilitar a tomada de decisão não seria condição única e suficiente para o avanço no número de transplantes no país.

É preciso, ao mesmo tempo, superar gargalos em outras variáveis, como estrutura logística, estrutura de manutenção de doadores, de equipes de captação e de transplantes disponíveis. Afinal, mais do que ter o consentimento da família, é imperioso efetivar a doação e transformar esse ato de amor em órgãos transplantados.

\section{CONCLUSÃO}

Ao contrário da noção de seres humanos plenamente racionais, a Economia Comportamental evidencia que somos racionalmente limitados, possuímos capacidade computacional limitada e funcionamos de forma muito mais automática e visceral na maioria das vezes. Tomar decisões e fazer escolhas é cansativo, e, desse modo, nosso cérebro "poupa" energia ao facilitar a tomada de decisão, seguindo "regras de bolso" (heurísticas mentais). Compreender como tomamos nossas decisões e o que nos influencia é peça-chave para uma política pública sobre doação de órgãos de sucesso. Precisamos focarnos no usuário final das políticas e intervenções, e questionar-nos sobre o que o motiva, o que ele valoriza e quais trade-offs ele faz ao escolher diferentes cursos de ação.

A forma como enquadramos a informação a ser apresentada pode aproximar o familiar do conceito de um doador ao invés de um não doador. O uso de reforços sociais provê referência e facilita a avaliação sobre o tema. E, por último, quanto mais automática puder ser a decisão de doar, maiores serão as chances de aumentarem as taxas de consentimento no país.

As características comportamentais aqui discutidas podem inspirar desenhos de campanhas de conscientização mais assertivas. Não basta falar sobre doação de órgãos, uma vez que o enquadramento inadequado pode mais afastar do tema do que aproximar. Reforçar associações positivas ao tema da doação de órgãos (vida, renascimento, vitória, alegria), ao invés de associações negativas (morte, perda, luto, sofrimento), parece ser um bom caminho. Nenhum indivíduo morre para doar, pois a morte não é uma escolha. Já doar sim, é uma escolha. E essa escolha só pode gerar vida.

No caminho da construção de uma cultura doadora no Brasil, o uso do poder das normas sociais em campanhas, ou como input no momento da tomada de decisão pode igualmente facilitar a aproximação do tema. É necessário que sejam produzidos novos estudos e dados acerca dessa questão. Saber quantos brasileiros aprovam a doação de órgãos e quantos já avisaram seus familiares que são doadores são dados poderosos que tendem a ser aliados à tarefa de conscientização.

A alteração da regra pré-definida para doação de órgãos (rumo ao consentimento presumido) é um caminho que muitos países europeus têm escolhido como forma de enfrentamento do déficit de órgãos. No presente momento, acreditamos não haver no Brasil condições institucionais para mudança do sistema. No entanto, apesar do sistema brasileiro exigir consentimento explícito acerca da doação de órgãos, onde a regra pré-definida é não ser doador, esforços de abordagem familiar inspirados na presente discussão comportamental e melhor desenho do ambiente de escolhas (nudge) podem contribuir significativamente para o processo decisório familiar e com a construção de preferências acerca da doação.

O presente estudo ressalta que a reflexão aqui conduzida de características comportamentais capazes de iluminar e contribuir para a compreensão da tomada de decisão na doação de órgãos não é exaustiva. Diversos outros conceitos comportamentais e futuros estudos podem fornecer a visão ainda mais rica dessa decisão e devem ser avaliados.

Por fim, conclui-se, a partir da presente análise, que as características comportamentais aqui relatadas apresentam potencial explanatório relevante. Incorporálas, portanto, ao modelo atual de tomada de decisão de doação de órgãos aproxima os esforços no tema do real tomador de decisão: o ser humano. É ele quem doa. É ele quem salva. É ele quem decide. 


\section{ABSTRACT}

Recent data shows that $43 \%$ of the families in Brasil still do not autorize organ donation. Therefore understanding which variables play a role at this moment and the complex decision-making process on organ donation is necessary so that new efforts seeking to raise families consent in the country can be implemented. This present work aims: a) to introduce behavioral concepts with the potential to enrich our understanding about the decision making process on organ donation like framing, status quo, social norms, inertia and procrastination; b) to bring forward experiments and public policies already applied worldwide inspired in this behavioral concepts and its results. This reflexive study is based on the Behavioral Economics findings. We conclude from this current reflection that these behavioral concepts present relevant explanatory potential. To incorporate them in the decision-making process model indicates not only a possible contribution to families approach, but also to the construction of campaigns and in the future for a better choice architecture design (nudge).

Keywords: Organ Donation; Behavioral Economics; Decision Making.

\section{REFERÊNCIAS}

1 Ashraf N. Rx: Human Nature: How behavioral economics is promoting better health around the world. Harvard Business Review. 2013;91(4):119-25.

2 Kahneman, D. Thinking fast and slow. New York: Farrar, Srauss and Groux. 2011.

3 Mumamatsu R, Fonseca P. Psicologia e Economia na explicação da escolha intertemporal. Revista de Economia Mackenzie. São Paulo. 2008;6(1):87-112.

4 Registro Brasileiro de Transplantes [base de dados da internet]. São Paulo: Associação Brasileira de Transplante de Órgãos. [acesso em: 25 de fevereiro de 2016]. Disponível em: http://www.abto.org.br/abtov03/Upload/file/ RBT/2015/anualnassociado.pdf

5 Sanders M, Hallworth M. Applying behavioral economics in a health policy context: Dispatches from the front lines. In: Roberto CA, Kawachi I. (Org.). Behavioral Economics and Public Health. Oxford: Oxford University Press; 2015:265-97.

6 Johnson EJ, Goldstein D. Do Default save lives? Science. 2003;302:1338.

7 Kahneman D, Tversky A. Prospect theory: an analysis of decision under risk. Econometrica. 1979;47:263-91.

8 Tversky A, Kahneman D. The framing of decisions and the psychology of choice. Science. 1981;211:453-58.

9 Peng J, Hongsheng L, Miao D, Feng X, Xiao W. Five different types of framing effects in medical situation: a preliminary exploration. Iranian Red Crescent Medical Journal. 2013;15: 161-5.
10 Levin IP, Schneider SL, Gaeth GJ. All frames are not created equal: a typology and critical analysis of framing effects. Organizational Behavior and Human Decision Processes. 1998;76:149-88.

11 Bigman CA, Cappella JN, Hornik RC. Effective or ineffective: attribute framing and the human papillomavirus (HPV) vaccine. Patient Education and Counseling. 2010; 81: S70-S76.

12 Gong J, Zhang Y, Feng J, Huang Y, Wei Y, Zhang W. Influence of framing on medical decision making. EXCLIJournal. 2013;12:20-29.

13 Linville PW, Fischer GW, Fischhoff B. AIDS risk perceptions and decision biases. In: J.B. PRIOR, G.D. REEDER (editors). The social psychology of HIV infection. Hillsdale: Lawrence Erlbaum; 1993;5-38.

14 Reyna VF, Brainerd CJ. Dual processes in decision making and developmental neuroscience: a fuzzy trace model. Developmental Review. 2011;31:180-206.

15 Schultz P, Nolan JM, Cialdinil RB, Goldstein NJ, Griskevicius V. The Constructive, Destructive, and Reconstructive Power of Social Norms. Psychological Science. 2007;18(5):429-34.

16 Thaler R, Sunstein C. Nudge: o empurrão para a escolha certa. Rio de Janeiro: Elsevier. 2008

17 Childress JF, Liverman CT, editores. Organ Donation: Opportunities for Action. The National Academic Press: 2006. 